\title{
Mobile Apps for teaching Physics: using applications in Latvian schools
}

\author{
Loreta Juškaite \\ Riga Technical University Distance Education Study Centre (RTU DESC)
}

\section{INTRODUCTION}

Observed trends in education: the focus is set no longer on how to acquire the technical skills of using mobile apps, but on the methodological skills of using mobile apps, which requires continuous support from the school's administration and a significant amount of time to invest directly in developing the teachers' professional competence, which in turn can be realized with appropriate learning resources. When using technologies to develop young people's skills necessary for the labour market, it is not enough to invest in the acquisition of technology; the use of technologies should be aligned with both the specific content of the subject and its teaching methodology. Teachers of physics do not have sufficient methodological support and practice in the purposeful use of mobile apps in the learning process. Frequency of technology use and purposefulness in the learning process are often discussed. It is also necessary to consider that their integration in the learning process takes time - so that the teacher can acquire the opportunities offered by technologies both technically and methodically.

Limitations of the Study: Reaching Physics teachers who had experience with mobile app integration, more specifically, using mobile apps in the Physics subject context was quite difficult since education, indeed, mobile app use in Physics education is relatively new for the Latvian education context. The small number of participants (teachers) limited a diversity of the data collected in terms of criteria referred while selecting mobile apps.

\section{MATERIAL AND METHODS}

For further analysis, all the responses of the participants for the interview was imported to SPSS qualitative data analysis software. The utilization of a qualitative data analysis tool allowed for easily storing, organizing and analysing data. In addition to the data analysis of qualitative data, quantitative data gathered from the evaluation form was also included? Quantitative data gathered in the study was imported, organized and analysed through Microsoft Excel.

\section{RESULTS}

For mobile apps used in Physics education, teachers were asked to share for which purposes they integrated mobile apps into education and, they were asked to explain what affordances mobile apps had in the Physics subject context. Teachers generally used apps for content presentation, assessment, communication and sharing, measurement. Affordances of mobile apps for the Physics subject context were explained in terms of authenticity and personalization.

\section{DISCUSSION}

How do Physics teachers use mobile apps in education? For mobile apps used, the teachers were asked to describe how integrated mobile apps into education and which affordances they thought mobile apps had within the Physics subject context. Teachers were asked to explain what kind of mobile apps were used and for which purposes (communication, interaction, content presentation, sharing, collaboration, etc.). For example, for students to develop content or educational products, teachers preferred apps such as App Inventor, Scratch \& Arduino. The number of participants: 1547 students and 67 physics teachers. Almost all the teachers $(n=64)$ agreed that mobile app integration into Physics subject activities could promote personalization that meant students could reach content with ease, they could perform autonomous learning, making research, calculations or measurements during activities and they could continue learning without time or place constrictions spending less time.

\section{CONCLUSION}

Mobile apps are constantly and rapidly evolving, and there is practically no social domain where they would not be used, including education. The use of different mobile apps resources offers a lot of possibilities:

- organizing an interactive learning process;

- demonstrating and simulating physical processes;

- providing access to a wide variety of resources;

- processing the data - both for calculations, for the visualization of results and for modelling processes.

When deciding to use mobile technologies in the physics learning process, the teacher should be sure that this is the most effective tool in the situation.

\section{KEYWORDS}

Mobile apps, physics education process, skills 